\title{
Concentric and Eccentric Pedaling-Type Interval Exercise on a Soft Robot for Stable Coronary Artery Disease Patients: Toward a Personalized Protocol
}

Daniel P Fitze ${ }^{1 *}$, MSc; Martino Franchi ${ }^{1,2^{*}}$, MSc, PhD; Werner L Popp ${ }^{3,4}$, MSc, PhD; Severin Ruoss ${ }^{1}, \mathrm{MSc}, \mathrm{PhD}$; Silvio Catuogno 2 , MA; Karin Camenisch ${ }^{2}$, MSc; Debora Lehmann ${ }^{2}$, MSc; Christian M Schmied ${ }^{5}$, PD Dr med; David Niederseer ${ }^{5}, \mathrm{MD}, \mathrm{PhD}$, BSc; Walter O Frey ${ }^{2}$, Dr med; Martin Flück ${ }^{1}, \mathrm{MSc}, \mathrm{PhD}$

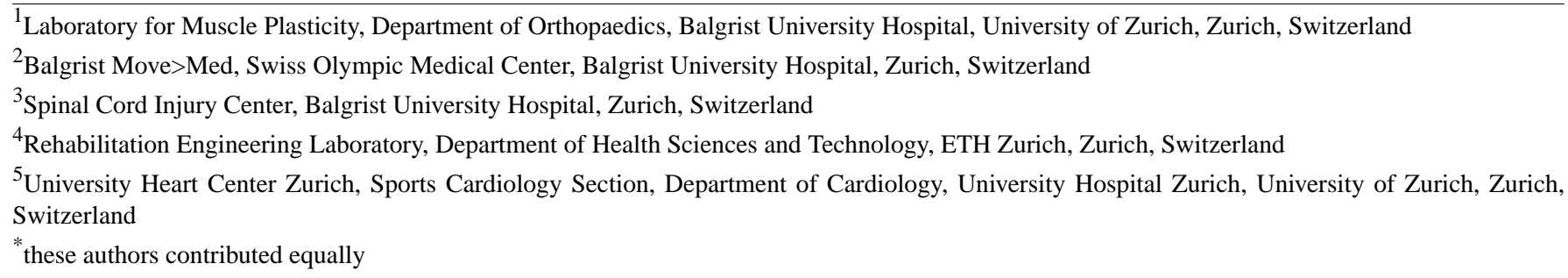

\section{Corresponding Author:}

Martin Flück, MSc, PhD

Laboratory for Muscle Plasticity

Department of Orthopaedics, Balgrist University Hospital

University of Zurich

Balgrist Campus

Lengghalde 5

Zurich, 8008

Switzerland

Phone: 41445107350

Email: mflueck@ research.balgrist.ch

\section{Abstract}

Background: Cardiovascular diseases are the leading causes of death worldwide, and coronary artery disease (CAD) is one of the most common causes of death in Europe. Leading cardiac societies recommend exercise as an integral part of cardiovascular rehabilitation because it reduces the morbidity and mortality of patients with CAD. Continuous low-intensity exercise using shortening muscle actions (concentric, $\mathrm{CON}$ ) is a common training modality during cardiovascular rehabilitation. However, a growing clinical interest has been recently developed in high-intensity interval training (HIIT) for stable patients with CAD. Exercise performed with lengthening muscle actions (eccentric, ECC) could be tolerated better by patients with CAD as they can be performed with higher loads and lower metabolic cost than CON exercise.

Objective: We developed a clinical protocol on a soft robot to compare cardiovascular and muscle effects of repeated and work-matched CON versus ECC pedaling-type interval exercise between patients with CAD during cardiovascular rehabilitation. This study aims to ascertain whether the developed training protocols affect peak oxygen uptake $\left(\mathrm{VO}_{2 \text { peak }}\right)$, peak aerobic power output $\left(\mathrm{P}_{\text {peak }}\right)$, and parameters of muscle oxygen saturation $\left(\mathrm{SmO}_{2}\right)$ during exercise, and anaerobic muscle power.

Methods: We will randomize 20-30 subjects to either the CON or ECC group. Both groups will perform a ramp test to exhaustion before and after the training period to measure cardiovascular parameters and $\mathrm{SmO}_{2}$. Moreover, the aerobic skeletal muscle power $\left(\mathrm{P}_{\text {peak }}\right)$ is measured weekly during the 8-week training period using a simulated squat jump and a counter movement jump on the soft robot and used to adjust the training load. The pedaling-type interval exercise on the soft robot is performed involving either $\mathrm{CON}$ or ECC muscle actions. The soft robotic device being used is a closed kinetic chain, force-controlled interactive training, and testing device for the lower extremities, which consists of two independent pedals and free footplates that are operated by pneumatic artificial muscles.

Results: The first patients with CAD, who completed the training, showed protocol-specific improvements, reflecting, in part, the lower aerobic training status of the patient completing the CON protocol. Rehabilitation under the CON protocol, more than 
under the ECC protocol, improved cardiovascular parameters, that is, $\mathrm{VO}_{2 \text { peak }}(+26 \% \mathrm{vs}-6 \%)$, and $\mathrm{P}_{\text {peak }}(+20 \%$ vs $0 \%)$, and exaggerated muscle deoxygenation during the ramp test (248\% vs $49 \%)$. Conversely, markers of metabolic stress and recovery from the exhaustive ramp test improved more after the ECC than the CON protocol, that is, peak blood lactate $(-9 \%$ vs $+20 \%)$ and peak $\mathrm{SmO}_{2}(+7 \%$ vs $-7 \%)$. Anaerobic muscle power only improved after the CON protocol (+18\% vs $\left.-15 \%\right)$.

Conclusions: This study indicates the potential of the implemented CON and ECC protocols of pedaling-type interval exercise to improve oxygen metabolism of exercised muscle groups while maintaining or even increasing the $\mathrm{P}_{\text {peak }}$. The ECC training protocol seemingly provided a lower cardiovascular stimulus in patients with CAD while specifically enhancing the reoxygenation and blood lactate clearance in recruited muscle groups during recovery from exercise.

Trial Registration: ClinicalTrials.gov NCT02845063; https://clinicaltrials.gov/ct2/show/NCT02845063

(JMIR Res Protoc 2019;8(3):e10970) doi: 10.2196/10970

\section{KEYWORDS}

cardiovascular rehabilitation; concentric and eccentric exercise; high-intensity interval training; muscle oxygen saturation; near-infrared spectroscopy; peak oxygen uptake; ramp test; skeletal muscle power; soft robot

\section{Introduction}

Diseases of the cardiovascular system cause $>4$ million deaths annually in Europe, and coronary artery disease (CAD) is one of the most common causes responsible for approximately 1.8 million deaths [1]. According to the Swiss Federal Statistical Office, diseases of the cardiovascular system are the third most frequent cause of hospitalization and the most frequent cause of death in Switzerland [2,3]. The inflammatory process of atherosclerosis is the main cause of CAD [4]. Progression of the disease increases the risk of angina pectoris, myocardial infarction, and cardiac arrest.

According to the Swiss Heart Foundation, common risk factors for CAD are hypertension, hyperlipidemia, obesity, diabetes mellitus, smoking, and physical inactivity [5]. Various studies have shown that exercise reduces morbidity and mortality of patients with CAD [6-8]. Positive effects of exercise in patients with CAD include improved cardiovascular and muscular function, quality of life, and the reduction of depressive symptoms and psychological stress [9]. The molecular mechanisms on how exercise is beneficial for patients with CAD range from the normalization of endothelial dysfunction to vasculogenesis through endothelial progenitor cells [10]. Exercise is, therefore, recommended by leading cardiac societies as an integral part of cardiovascular rehabilitation [11].

The continuous low-to-moderate-intensity exercise was traditionally the training modality chosen for cardiovascular rehabilitation. Although this training method is considered to be safe and practicable and has almost no contraindications for stable patients with CAD, a growing clinical interest in high-intensity interval training (HIIT) has been recently developed for stable patients with CAD [12]; this type of training is characterized by high-intensity periods of exercise, which are alternated by rest or low-intensity periods [13]. In terms of improving the peak oxygen uptake $\left(\mathrm{VO}_{2 \text { peak }}\right)$, HIIT has shown to produce superior outcomes compared with continuous low-to-moderate-intensity exercise in patients with CAD [14-16]. $\mathrm{VO}_{2 \text { peak }}$ has shown to be an independent predictor of morbidity and mortality of cardiovascular diseases [17-19]. Therefore, it represents an important index when evaluating adaptations to exercise regimes during cardiovascular rehabilitation.

Often the training is performed on a cycle ergometer; thus, it mainly involves shortening (concentric, $\mathrm{CON}$ ) muscle actions. However, lengthening (eccentric, ECC) muscle actions may be better tolerated by patients with CAD in clinical settings [20,21] because it can be performed with higher loads and lower metabolic cost than CON exercise [22-24], as shown by studies conducted on ECC ergometers [25-27]. Following such evidence, we have recently compared the cardiovascular and muscular adaptations to work-matched $\mathrm{CON}$ and ECC pedaling-type interval exercise of physically active and healthy subjects at an intensity being used during cardiovascular rehabilitation on a soft robot [28]; we found that indices of cardiovascular strain, such as $\mathrm{VO}_{2 \text { peak }}$, peak ventilation, peak cardiac output, and blood lactate (BL) values, were lower during ECC compared with CON exercise.

In this ongoing study, we developed a clinical protocol on a soft robot to compare work-matched CON with ECC pedaling-type interval exercise for patients with CAD during cardiovascular rehabilitation. This study aims to find out whether the developed training protocols affect $\mathrm{VO}_{2 \text { peak }}$, as well as aerobic muscle function (based on peak aerobic power output and muscle oxygen saturation), of patients with CAD during cardiovascular rehabilitation. We hypothesize that the $\mathrm{CON}$ and ECC protocol lead to distinct cardiovascular and muscular adaptations. This study presents preliminary data for cardiovascular and muscular adaptations to the CON and ECC exercise protocol in the first 2 patients with CAD.

\section{Methods}

\section{Recruitment and Ethics}

For the ongoing study [29], 10-15 patients for each experimental group are recruited by the Department of Cardiology of the University Hospital Zurich (Zurich, Switzerland). The study is approved by the Ethics Committee of the Canton of Zurich on March 23, 2015 (project number KEK-ZH-No. 2014-0319). All investigations were and will be conducted in accordance with the ethical standards of the Declaration of Helsinki of 1964. 


\section{Inclusion Criteria}

Subjects who meet all the following inclusion criteria may be included in the study: aged between 20 and 70 years; stable coronary heart patients without ischemia; left ventricular ejection fraction $>50 \%$; drug therapy with angiotensin-converting enzyme inhibitors; $\mathrm{VO}_{2 \text { peak }}$ of $>86 \%$ of the medical target value; voluntary participation in the study; and written informed consent.

\section{Exclusion Criteria}

If one or more of the following exclusion criteria are met, subjects cannot be included in the study: relevant valvular heart disease; arterial hypertension (blood pressure at rest >140/90); arrhythmogenic cardiomyopathy; angiotensin-converting enzyme inhibitor intolerance; contraindication for ethical reasons; known or suspected noncompliance with the study plan; drug or alcohol disease; the inability of a patient to follow the study procedure (eg, owing to language problems, mental illnesses, and dementia); participation in another clinical study within the last 30 days prior inclusion and during the study; and other clinically significant comorbidities (cardiac arrhythmia, renal insufficiency, hepatic dysfunction, connective tissue disease-Marfan syndrome, Ehlers-Danlos syndrome).

\section{Clinical Background of Patients}

The first patient is a 63-year-old male patient with a known coronary 3-vessel disease. Twelve years ago, he underwent a coronary-aortic bypass surgery procedure with 3 grafts in the setting of an acute elevation of the ST-segment of the electrocardiogram, indicating a total occlusion of a coronary artery (ie, ST-elevation myocardial infarction) 1 month earlier. The left ventricular systolic function appeared normal. The last coronary angiography was 3 years ago where 2 drug-eluting stents were deployed. His cardiovascular risk profile comprises arterial hypertension, previous smoking (30 pack-years), hypercholesterinemia, diabetes, and positive family history for a premature cardiovascular disease. The arterial hypertension is currently well treated with combination therapy of perindopril, indapamide, and amlodipine. Diabetes did not necessitate treatment. Hemoglobin A1c, a long-term indicator of the quality of glucose control in diabetes, is currently $7.1 \%$. Furthermore, he is on aspirin, bisoprolol, and rosuvastatin. Currently, he is free of symptoms; however, in light of secondary preventive aims, cardiovascular rehabilitation is warranted.

The second patient is a 62-year-old male who experienced an ST-elevation myocardial infarction 2 years earlier. The left anterior descending artery was successfully treated with 3 drug-eluting stents. On echocardiography, a normal left ventricular ejection fraction was noted; however, with regional wall motion abnormalities corresponding to the territory of the infarction (anterior and anteroseptal). His cardiovascular risk profile comprises a history of smoking (20 pack-years), treated hypercholesteremia, obesity (body mass index, $30 \mathrm{~kg} / \mathrm{m}^{2}$ ), and psychosocial stress. His present medication comprises aspirin, bisoprolol, lisinopril, and rosuvastatin.
Both patients are currently free of symptoms; however, in light of secondary preventive aims, cardiovascular rehabilitation in both patients is warranted.

\section{Study Design}

This study can be divided into 3 periods (Figure 1). The training on the soft robot is performed following either a CON or ECC protocol. Before the training period (PRE) during the first week, subjects complete a ramp test on a cycle ergometer to assess cardiovascular and aerobic muscular parameters. Subjects are then allocated into a CON or ECC group. In the second week, there are 2 training sessions to familiarize subjects with exercise on the soft robot. Before the 2 familiarizations and before every third training session, anaerobic muscle power is monitored using 2 power tests on the soft robot. Throughout the 8-week training period from the third to the tenth week, a pedaling-type interval exercise on the soft robot is completed, involving either $\mathrm{CON}$ or ECC muscle actions. The training is performed 3 times a week on nonconsecutive days. The training volume and intensity are progressively increased over the 8-week training period. In addition, the training load, training power, and positive or negative work are measured in all training sessions on the soft robot to monitor the training stimulus. After the training period (POST), subjects repeat the ramp test on the cycle ergometer to acquire POST values.

\section{Ramp Test}

The ramp test is completed in the exercise physiology lab of the Swiss Olympic Medical Center Balgrist Move>Med to determine cardiovascular parameters based on spiroergometry $\left(\mathrm{VO}_{2 \text { peak }}, \mathrm{P}_{\text {peak }}\right.$, heart rate $[\mathrm{HR}]$, and blood pressure $)$ and $\mathrm{SmO}_{2}$ based on near-infrared spectroscopy (NIRS). Before the ramp test, anthropometric data (height and body mass) of subjects are measured, and the body mass index is calculated. Subsequently, subjects fill out the Physical Activity Readiness Questionnaire. A resting electrocardiogram measurement is then performed and checked by a physician to ensure that subjects can conduct the ramp test. The exercise electrocardiogram during the ramp test is continuously monitored by the physician.

Subjects perform the test in an upright sitting position in an air-conditioned laboratory on an electrically braked cycle ergometer (ergoselect 200, ergoline). To determine $\mathrm{VO}_{2 \text { peak }}$, pulmonary gas exchange is measured with a spiroergometry measuring system (MetaLyzer 3B-R2, CORTEX Biophysics). The HR is measured continuously using an HR monitor (SUUNTO t6d, SUUNTO). Systolic and diastolic blood pressure (Sys BP and Dia BP, respectively) are measured on the upper right arm every 2 minutes using a BP monitor (Suntec Tango+, Suntec Medical Inc). In addition, BL is measured by collecting a sample of blood from the earlobe every 2 minutes using a lancing device (Akku-Check, Safe-T-Pro-Plus, Roche Diabetes Care) and a BL monitor (Biosen C-Line, EKF-diagnostic). Details on the NIRS measurement during the ramp test are provided in the following section. 
Figure 1. The study design timeline. CON: concentric protocol; ECC: eccentric protocol; PRE: before training period; POST: after training period; $\mathrm{VO}_{2 \text { peak }}$ : peak oxygen uptake; $\mathrm{P}_{\text {peak }}$ : peak aerobic power output; HR: heart rate; BP: blood pressure; BL: blood lactate; NIRS: near-infrared spectroscopy; $\mathrm{SmO}_{2}$ : muscle oxygen saturation.

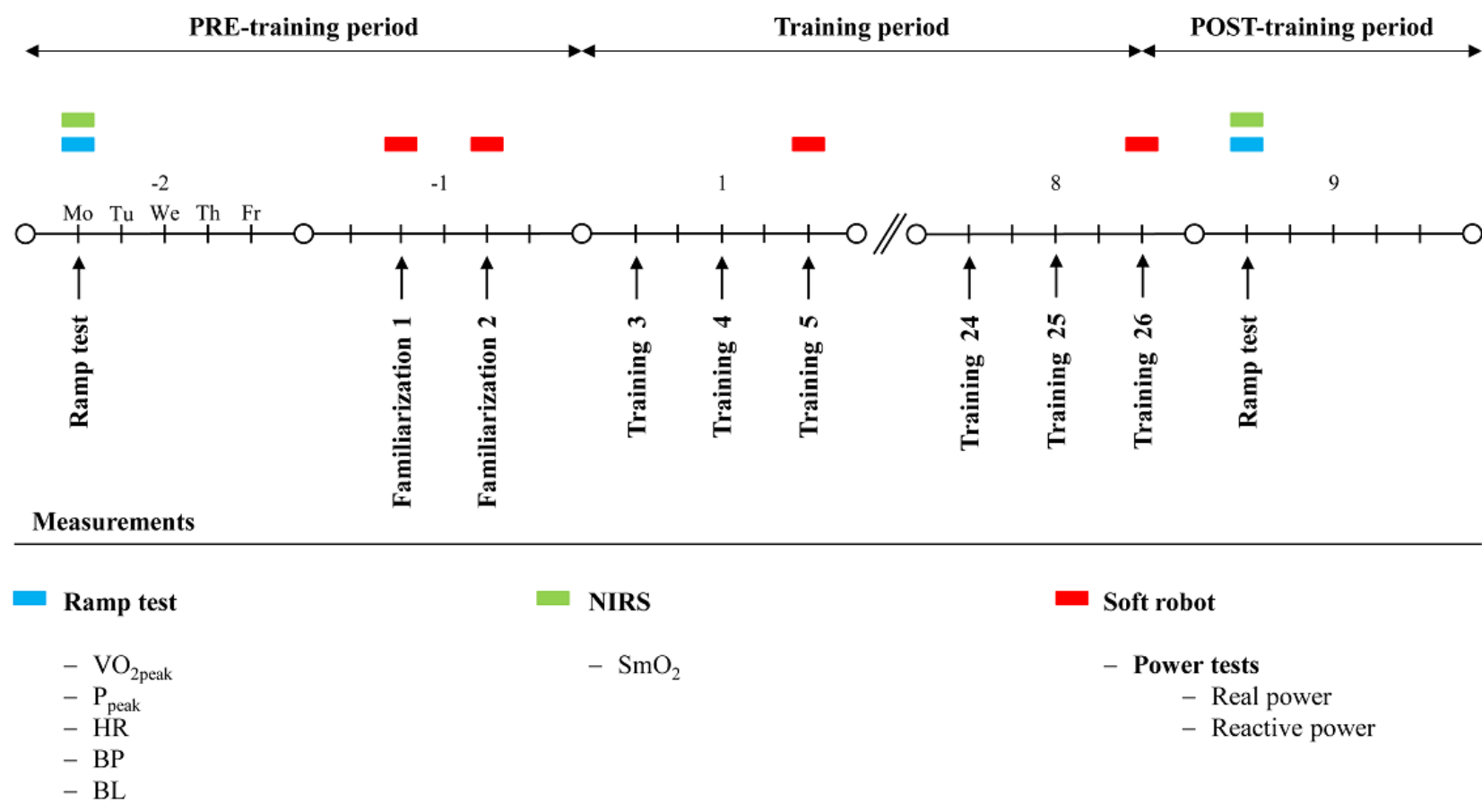

The test protocol is modified as described elsewhere [30]. It starts with a 3-minute rest period, where subjects are asked to sit still on the cycle ergometer without pedaling, while maintaining a normal breathing pattern. Subsequently, subjects begin pedaling at an initial power of $25 \mathrm{~W}$. The power is then increased in $5-\mathrm{W}$ increments every 20 seconds $\left(15 \mathrm{~W}^{*} \mathrm{~min}^{-1}\right)$. Subjects are asked to keep a constant self-chosen pedal cadence throughout the test (optimally between 70 and $100 \mathrm{rpm}$ ). The test is stopped when subjects experience volitional exhaustion and are not able to maintain the target pedal cadence. After the stop, there is an 8-minute rest period.

\section{Near-Infrared Spectroscopy}

A muscle oxygen monitor (Moxy, Fortiori Design LLC), based on the NIRS technology, is used to measure $\mathrm{SmO}_{2}$ during the ramp test noninvasively. The Moxy Monitor uses 4 different light sources covering wavelengths ranging from 630 to 850 $\mathrm{nm}$ and a modified Beer-Lambert law to perform measurements of $\mathrm{SmO}_{2}$ [31]. $\mathrm{SmO}_{2}$ refers to the percentage of hemoglobin and myoglobin that have bound oxygen of the investigated muscle [31].

The sensor is placed on the lower third of the m. vastus lateralis in the middle of the muscle belly on the left leg of subjects (Figure 2). The sensor is placed $10 \mathrm{~cm}$ above the upper lateral point of the patella along the axis of the leg. After the placement, the NIRS device is covered with an adhesive nonwoven fabric to protect it from ambient light. Prior to the placement, if necessary, the skin site is shaved using a disposable razor (Gallant, Dynarex) and cleaned with an alcohol swab (Webcol,
Covidien). The sensor attachment is carried out using an attachment tape (Moxy Adhesive Attachments, Fortiori Design LLC). To protect the NIRS device from ambient light, it is covered with an adhesive nonwoven fabric (Hypafix, BSN Medical).

\section{Soft Robot}

\section{Description of the Soft Robotic Device}

A technical description of the soft robotic device (Allegro, Dynamic Devices, Zurich, Switzerland) to be used has been rendered before [28]. In brief, the Allegro soft robot is a closed kinetic chain, force-controlled interactive training, and testing device for the lower extremities. The Allegro device has a leg press layout and consists of two independent pedals and free footplates that are connected to pneumatic artificial muscles through shafts and levers. The seat has an adjustable height and a declinable backrest.

Force application to the pedals is controlled through the supply of pressurized air to the artificial muscles via a software-controlled actuation mechanism for each work cycle. The forces and speeds being produced by the artificial muscles, and those being applied by the user, are controlled during each cycle and displayed via a monitor. This visual feedback allows the user to tune its performance to the target workload through a work cycle. In addition to programmable exercise protocols, the Allegro is equipped with several fundamental test protocols allowing to asses motor accuracy, peak force, positive impulse, negative impulse, net impulse, and power for cyclic movements, reaction time, force control, and force steadiness. 
Figure 2. Moxy monitor placement.

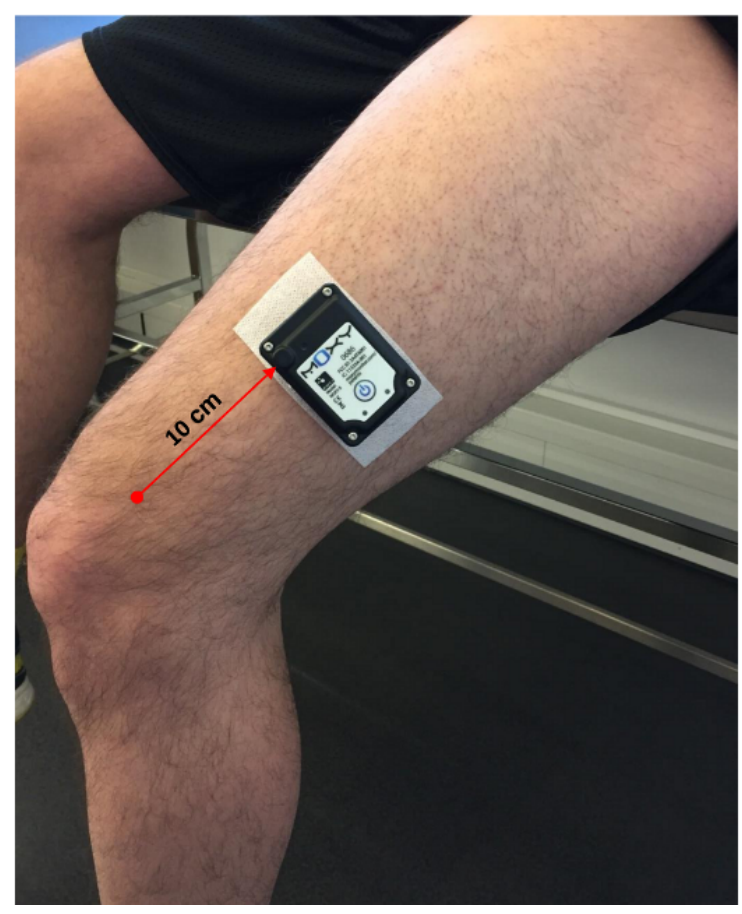

\section{Pedaling-Type Interval Exercise}

The supervised training is carried out at the Swiss Olympic Medical Center Balgrist Move>Med with the Cardio Power Training protocol on a soft robot (Allegro, Dynamic Devices). Subjects perform the training 3 times per week with a minimum rest period of $48 \mathrm{~h}$ between training sessions. The range of motion (ROM) and movement speed are audiovisually controlled through the integrated screen (Figure 3). Dotted yellow lines, the starting and end knee joint flexion angle and, thus, determine the ROM. During the work phase, the blue and red bar alternately move up and down and, thus, set the movement speed. Blue and red dots represent the current knee joint flexion angle of the left and right leg, respectively. Subjects aim to follow the 2 bars and adhere to the defined ROM. ROM is set to a knee joint flexion angle of $5^{\circ}-90^{\circ}$ and movement speed is $30 \mathrm{rpm}$. Each interval comprises 1-minute work and 1-minute passive rest period. Training volume and training load are progressively increased over the 8-week training period (Figure 3 ). For the CON group, the training intensity and volume are determined as follows. During the first 2 weeks, the external load is set to $65 \%$ of $\mathrm{P}_{\text {peak }}$ achieved on the cycle ergometer during the ramp test, and the training comprises 10 consecutive intervals. During the third and fourth week of training, the volume is increased to 15 intervals without changing the external load. During the fifth and sixth week of training, the external load is increased to $70 \%$ of $\mathrm{P}_{\text {peak }}$ while maintaining the volume. During the seventh and eighth week of training, the external load is further increased to $75 \%$ of $\mathrm{P}_{\text {peak }}$. For the ECC group, the calculated training loads are multiplied by factor 1.4 . To ensure that both groups perform the same external work, the ECC group completes only 7 and 11 intervals, respectively.

\section{Power Tests}

A Real Power and a Reactive Power test are performed on the soft robot to monitor anaerobic muscle power of the lower extremities. The power tests are performed before and after both familiarizations and every third training session.

The Real Power test is used to determine anaerobic muscle power during a simulated squat jump. The external load corresponds to $50 \%$ of the body mass per leg. Subjects are instructed to flex both legs until a knee joint flexion angle of $90^{\circ}$. With the command "Push," subjects have to extend both legs as fast as possible. Figure 4 (left) illustrates the provided visual feedback.

The Reactive Power test is used to determine the skeletal muscle reactive power during a simulated countermovement jump. The external load corresponds to $50 \%$ of the body mass per leg. Subjects have to flex and extend both legs as fast as possible. The test is considered valid if both legs reach a knee joint flexion angle of $90^{\circ}$. Figure 4 (right) illustrates the provided visual feedback.

In Figure 4, the blue and red lines show the knee joint flexion angle of the left and right leg versus time. Green zone, the target knee joint flexion angle of $90^{\circ}$.

A previous characterization has indicated high reliability and comparability for values of force and power between soft robot-based measurements of simulated squat jumps and force-plate measurements during real squat jumps [28]. 
Figure 3. Top: Display of the audiovisual feedback to control training on the soft robot. Bottom: Timeline for the progressive increase of training volume and intensity for the CON and ECC protocol, respectively. ROM: range of motion; CON: concentric protocol; ECC: eccentric protocol; $\mathrm{P}_{\text {peak: }}$ : peak power output (Source: Daniel Fitze, Dynamic Devices AG).
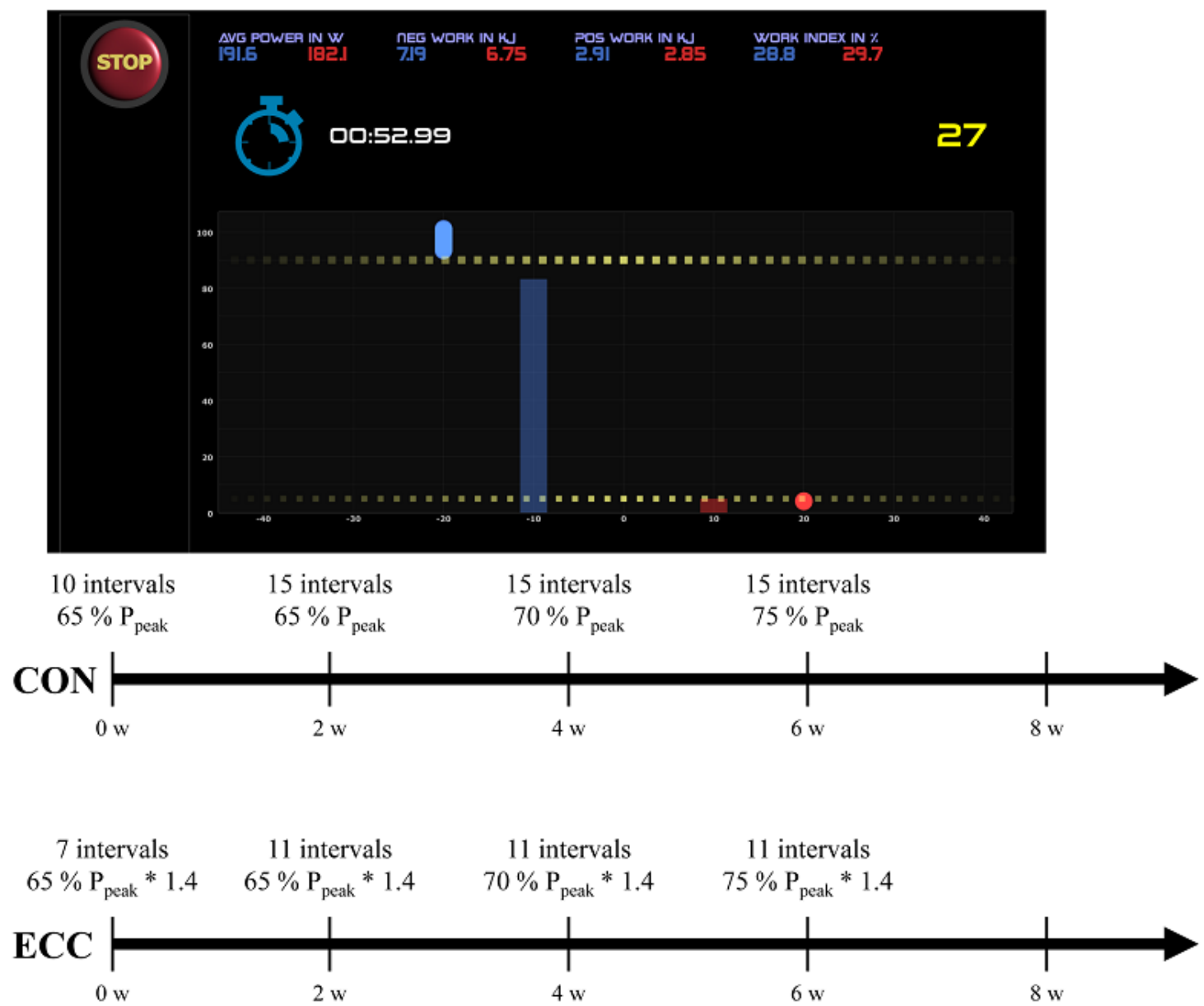

Figure 4. Left: Display of the visual feedback during the Real Power test on the soft robot. Blue and red lines, the knee joint flexion angle of the left and right leg versus time. Right: Display of the visual feedback during the Reactive Power test on the soft robot (source: Daniel Fitze, Dynamic Devices $\mathrm{AG})$.

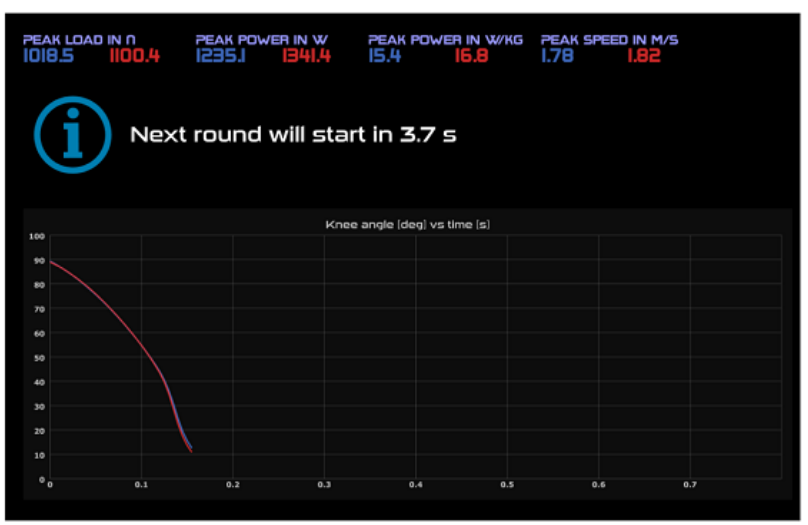

\section{Data Analysis}

\section{Ramp Test}

$\mathrm{VO}_{2 \text { peak }}$ is defined as the highest $\mathrm{VO}_{2}$ value averaged over a period of $30 \mathrm{~s}$. $\mathrm{P}_{\text {peak }}$ corresponds to the peak aerobic power output on the cycle ergometer. Peak heart rate $\left(\mathrm{HR}_{\text {peak }}\right)$ represents the peak 5-s HR value. Peak systolic and diastolic

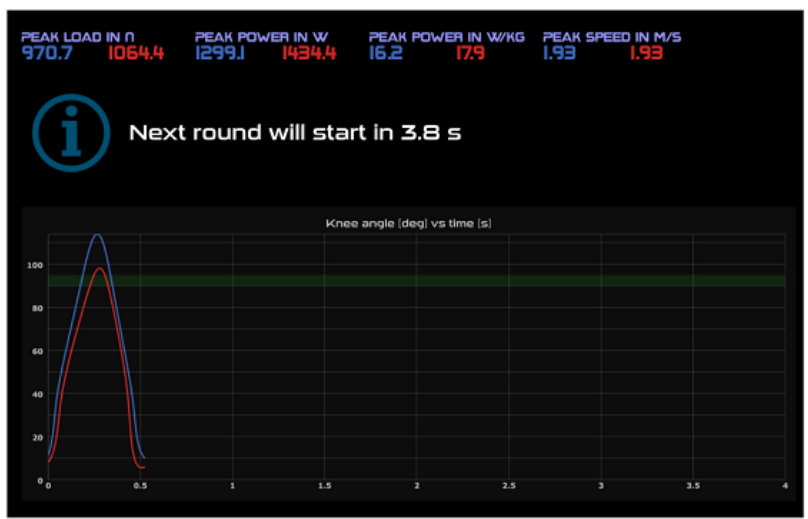

blood pressure (Sys $\mathrm{BP}_{\text {peak }}$, Dia $\mathrm{BP}_{\text {peak }}$, respectively), and peak blood lactate $\left(\mathrm{BL}_{\text {peak }}\right)$ define the measured peak values achieved during the ramp test.

\section{Near-Infrared Spectroscopy}

Figure 5 shows a representative example of the $\mathrm{SmO}_{2}$ course during the ramp test of a healthy subject including raw data, processed data, and different parameters. Data processing and 
analysis are performed using a data processing program (MATLAB 2015a, The MathWorks). $\mathrm{SmO}_{2}$ data are filtered using a second-order zero-phase shift Butterworth low-pass filter with a cut-off frequency of $0.03 \mathrm{~Hz}$. Data extraction is performed based on the description of the NIRS signal interpretation provided elsewhere [32]. $\mathrm{SmO}_{2 \text { baseline }}$ represents the mean value of the 3 -minute prerest period. The minimum $\mathrm{SmO}_{2}$ value during the ramp test $\left(\mathrm{SmO}_{2}\right.$ min $)$ is extracted by taking the last local minimum of the filtered $\mathrm{SmO}_{2}$ prior to reoxygenation. Furthermore, $\Delta_{\text {deoxygenation }}$ is the difference between $\mathrm{SmO}_{2 \text { baseline }}$ and $\mathrm{SmO}_{2 \text { min }}$; $t_{\text {deoxygenation }}$ is the time from the beginning of the ramp test until $\mathrm{SmO}_{2 \min }$ is reached; slope $_{\text {deoxygenation }}$ is calculated using $\Delta_{\text {deoxygenation }}$ over $t_{\text {deoxygenation, }}$ $\mathrm{SmO}_{2 \max }$ is defined as the highest value achieved within the 8-minute postrest period; $\mathrm{SmO}_{2}$ 1/2reoxygenation is defined as $50 \%$ of the difference between $\mathrm{SmO}_{2 \max }$ and $\mathrm{SmO}_{2 \min } ; \Delta_{1 / 2 \text { reoxygenation }}$ is the difference between $\mathrm{SmO}_{2}$ 1/2reoxygenation and $\mathrm{SmO}_{2 \min }$; $t_{1 / 2 \text { reoxygenation }}$ is defined as the time between $\mathrm{SmO}_{2 \min }$ and $\mathrm{SmO}_{2}$ $1 / 2$ reoxygenation ${ }$ slope $_{1 / 2 \text { reoxygenation }}$ is calculated using $\Delta_{1 / 2 \text { reoxygenation }}$ over $t_{1 / 2 \text { reoxygenation }}$; and $\mathrm{SmO}_{2 \text { overshoot }}$ represents the difference between $\mathrm{SmO}_{2 \max }$ and $\mathrm{SmO}_{2 \text { baseline. }}$.

\section{Soft Robot}

For the Real Power and Reactive Power test on the soft robot, the average and the peak value of the 4 test attempts are extracted.

\section{Statistical Analysis}

Data will be analyzed for interaction effects of the exercise type on training-induced alterations using a mixed analysis of variance with repeated measures using statistical software (SPSS Statistics 22; IBM). Effects will be localized posthoc with the least significant difference of Fisher. Furthermore, effect sizes and power will be estimated subsequently with publicly available G*Power software (gpower.hhu.de/). 
Figure 5. The representative example of the $\mathrm{SmO}_{2}$ course during the ramp test of a healthy subject including raw data, processed data, and different parameters. $\mathrm{SmO}_{2}$ : muscle oxygen saturation; t: time; min: minimum; max: maximum.

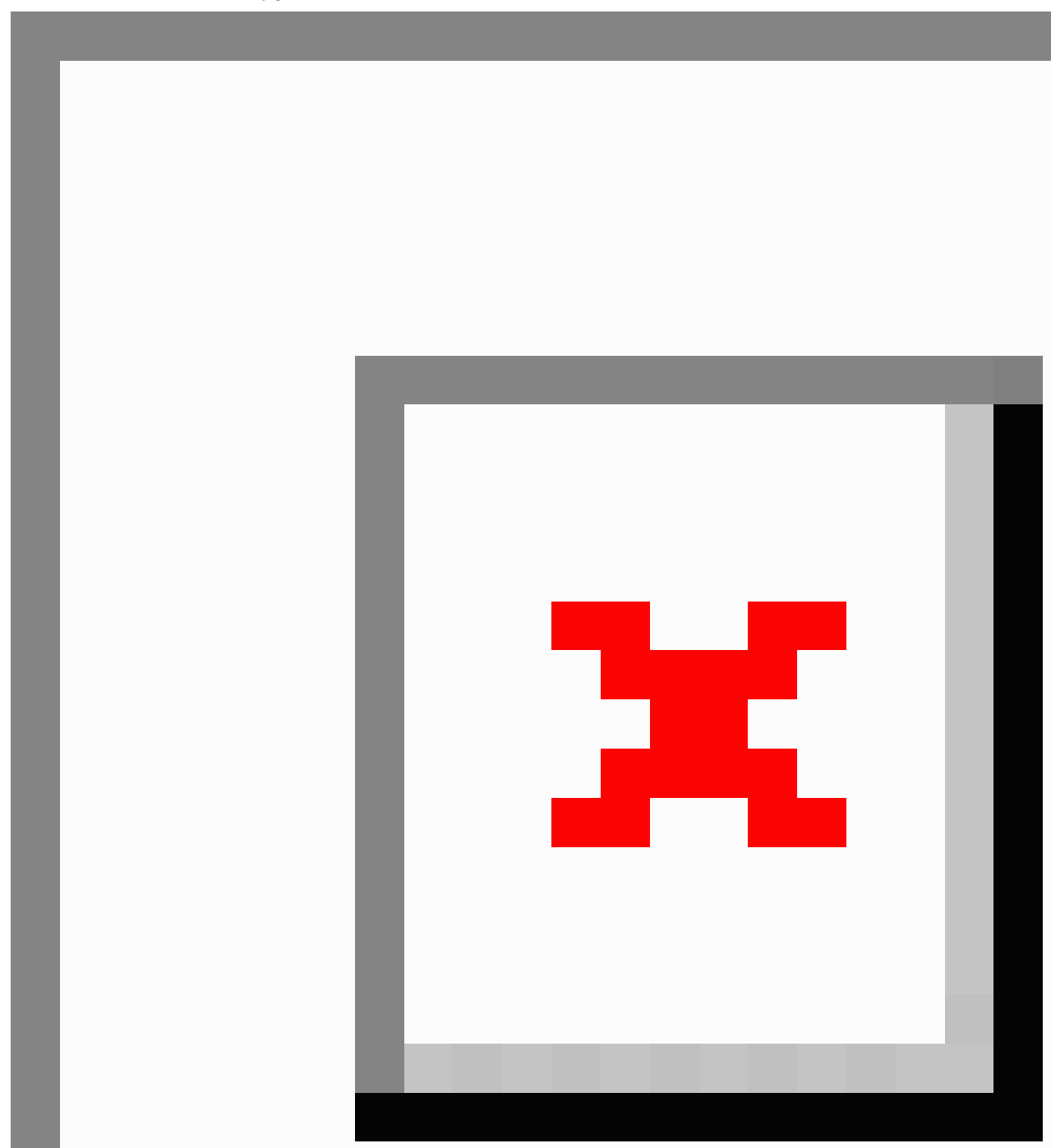

\section{Results}

\section{Description of Effect}

The results of the first 2 patients who completed the CON and ECC protocol, respectively, are listed below as percentage changes. Multimedia Appendix 1, and 3 present absolute PRE and POST values.

\section{Ramp Test}

Figure 6 shows training-induced percentage changes in cardiovascular performance. Before training, the patient completing the ECC protocol had better values of cardiovascular performance than the patient completing the $\mathrm{CON}$ protocol, that is, absolute $\mathrm{VO}_{2 \text { peak }}\left(3.16 \mathrm{vs} 1.94 \mathrm{~mL} \cdot \mathrm{O}_{2} \cdot \mathrm{min}^{-1}\right)$, relative $\mathrm{VO}_{2 \text { peak }}$ (29.01 vs $\left.20.9 \mathrm{~mL} \cdot \mathrm{O}_{2} \cdot \mathrm{min}^{-1} \cdot \mathrm{kg}^{-1}\right)$, and $\mathrm{P}_{\text {peak }}(250 \mathrm{vs} 150 \mathrm{~W}$ ). After training, the patient completing the $\mathrm{CON}$ protocol demonstrated an increased absolute $\mathrm{VO}_{2 \text { peak }}(+26 \%)$, relative $\mathrm{VO}_{2 \text { peak }}(+26 \%)$, and $\mathrm{P}_{\text {peak }}(+20 \%)$, when the ECC patient showed reduced values for absolute $\mathrm{VO}_{2 \text { peak }}(-7 \%)$ and relative $\mathrm{VO}_{2 \text { peak }}(-6 \%)$, while maintaining $\mathrm{P}_{\text {peak }}$. $\mathrm{HR}_{\text {peak }}$ and $\mathrm{BL}_{\text {peak }}$ concentration during exercise were increased by $28 \%$ and $24 \%$ after the CON protocol and $2 \%$ and $9 \%$ reduced after the ECC protocol, respectively. 


\section{Near-Infrared Spectroscopy}

Figure 7 shows training-induced percentage changes of $\mathrm{SmO}_{2}$ parameters. Details of the extracted $\mathrm{SmO}_{2}$ parameters can be found in the section data analysis. Gray shaded area refers to the observed baseline differences of the measurements prior to training. The minima of $\mathrm{SmO}_{2}$ during the ramp test were further reduced by training under either protocol, whereby changes being reflective of muscle deoxygenation were more increased after training for the $\mathrm{CON}$ respective to the ECC protocol, that is, $\mathrm{SmO}_{2 \min }, \Delta_{\text {deoxygenation }}, t_{\text {deoxygenation }}$, and slope deoxygenation. $_{\text {In }}$ contrast, $\mathrm{SmO}_{2 \max }$ and $\mathrm{SmO}_{2}$ overshoot increased in the patient completing the ECC protocol, while the values for these parameters decreased in the patient completing the CON protocol (Multimedia Appendix 2).

Figure 6. Training-induced changes of cardiorespiratory parameters in the first 2 patients completing the CON or ECC protocols. Bar graph of the percentage changes after versus before the training period (ie, POST vs PRE). $\mathrm{VO}_{2 \text { peak }}$ : peak oxygen uptake; $\mathrm{P}_{\text {peak }}$ : peak aerobic power output; $\mathrm{HR}_{\text {peak }}$ :

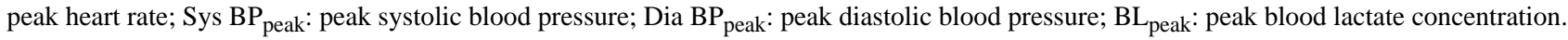

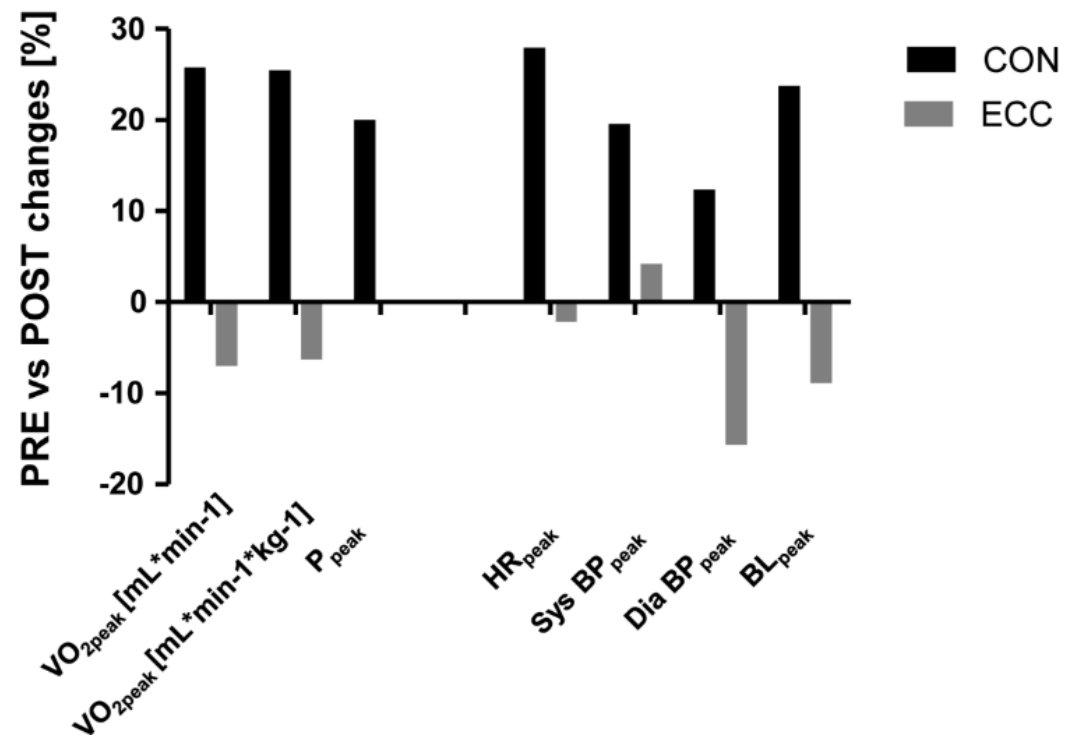


Figure 7. Training-induced changes of $\mathrm{SmO}_{2}$ parameters in the first 2 patients completing the respective CON or ECC protocols. Bar graph of the percentage changes POST versus PRE. $\mathrm{SmO}_{2}$ : muscle oxygen saturation; $\mathrm{t}$ : time; min: minimum; max: maximum.

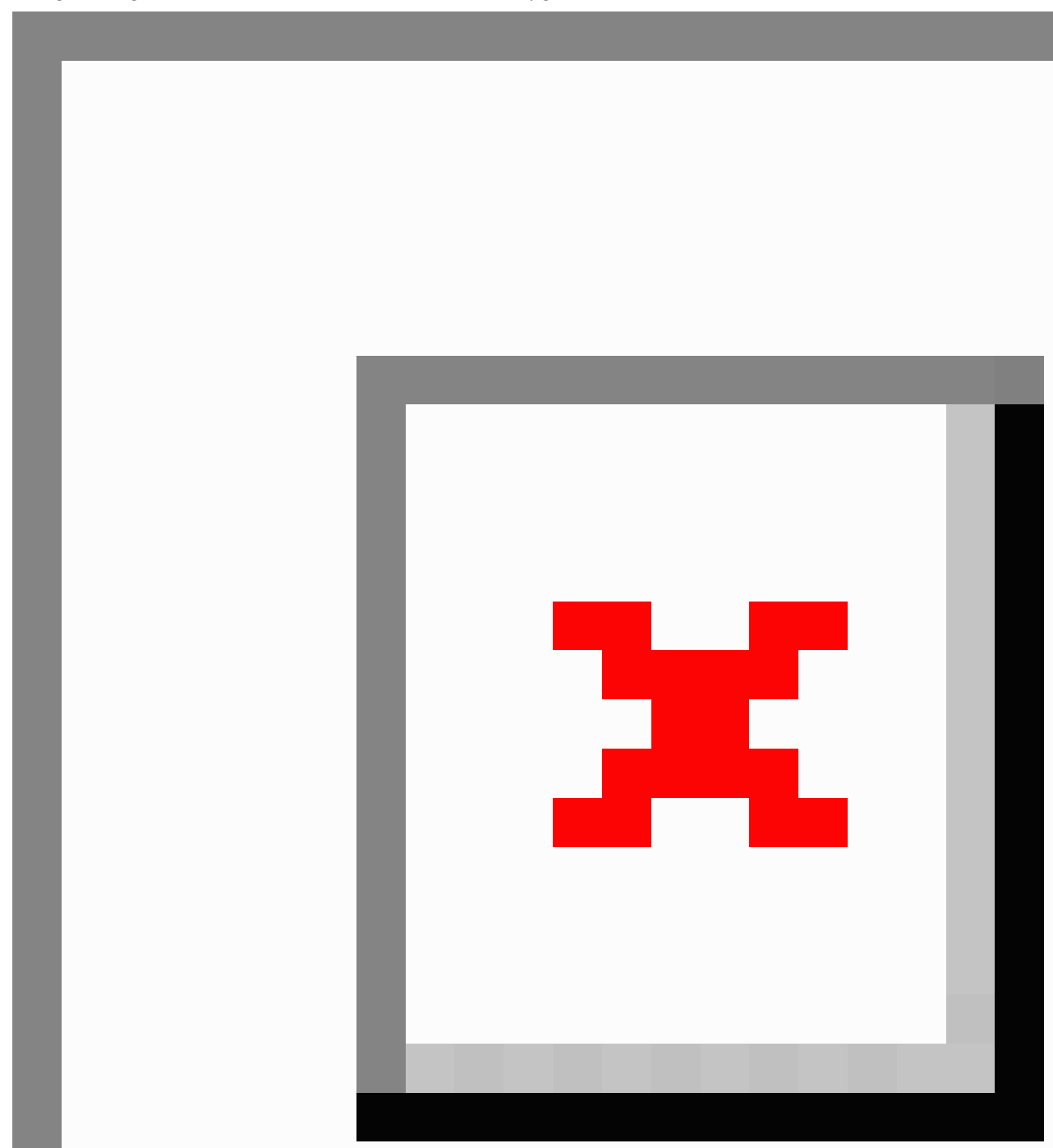

Before training, the patient entering the ECC protocol had 25\% and $23 \%$ higher peak real power values of the left and right leg, respectively, than the patient entering the CON protocol (Multimedia Appendix 3). In contrast, the peak power of the left and right leg in the reactive power test was $28 \%$ and $19 \%$, respectively, lower for the patient entering the ECC protocol than the patient entering the CON protocol.

Figure 8 shows training-induced percentage changes of anaerobic muscle function as assessed separately for both legs on the soft robot. The CON protocol exhibited an improvement in the average power $(+49 \%,+34 \%)$ and peak power $(+24 \%$, $+13 \%$ ) for the left and right leg during the real power test, when these values were reduced after the ECC protocol (left: $-25 \%$, $-25 \%$; right: $-8 \%,-5 \%$ ), despite a larger average increase in the training load. Power during the reactive power test was improved with both protocols, whereby leg differences revealed for the ECC protocol. 
Figure 8. Training-induced changes of the muscle performance on the soft robot for patients completing the respective CON or ECC protocols. Bar graph of the percentage changes POST (after the training period) versus PRE (before the training period). CON: concentric protocol; ECC: eccentric protocol; Avg: average; $\mathrm{t}_{\text {peak }}$ : time to peak.
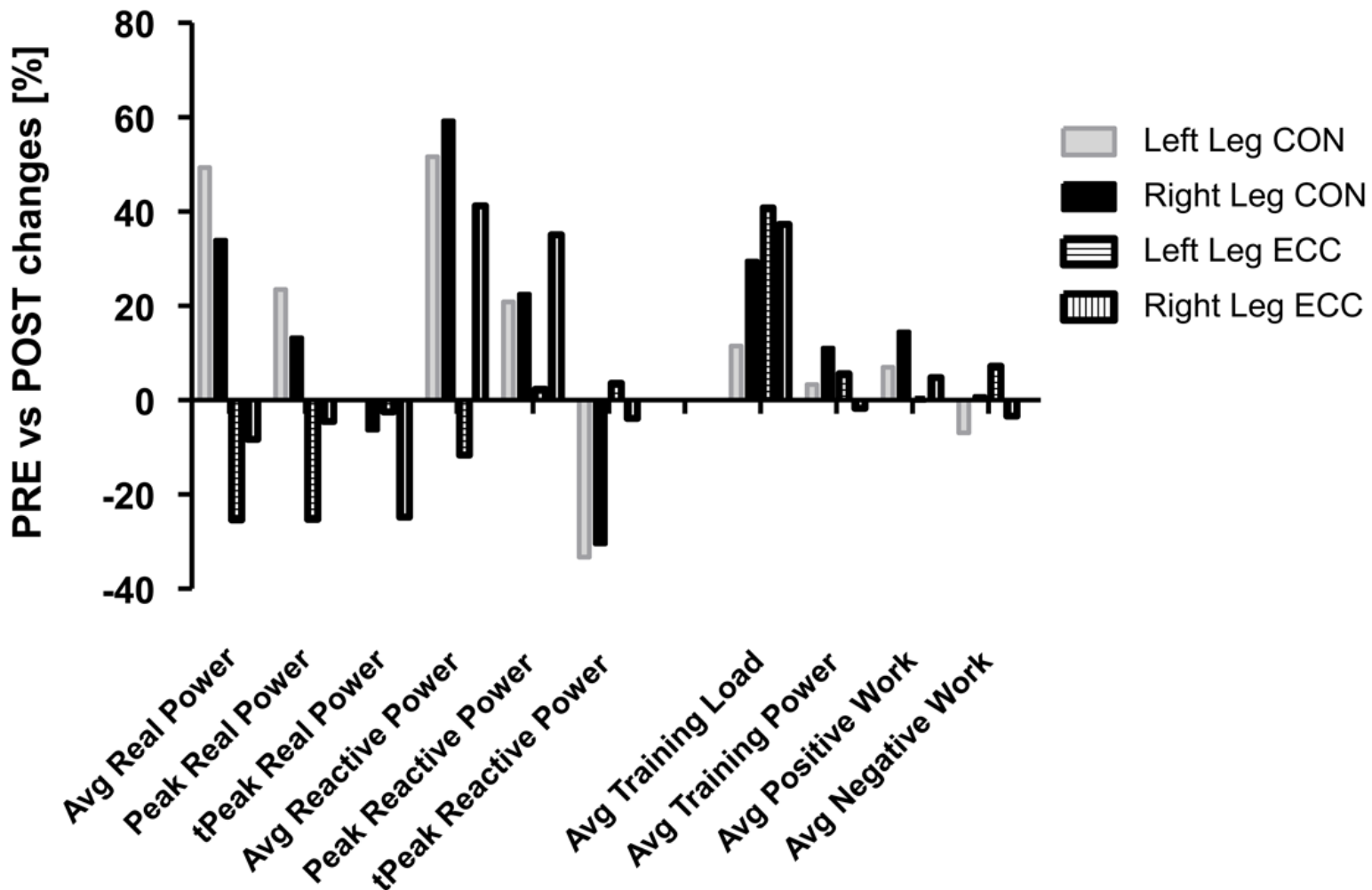

\section{Discussion}

\section{Principal Findings}

We developed a novel exercise protocol on an interactive soft robot to investigate the effects of work-matched $\mathrm{CON}$ versus ECC pedaling-type interval exercise on cardiovascular and muscular parameters of stable patients with CAD during cardiovascular rehabilitation.

One of the strengths of the protocol is that the measured cardiovascular and muscular parameters have well-documented prognostic relevance in patients with CAD. Furthermore, the combination of HIIT and ECC muscle actions in stable patients with CAD during cardiovascular rehabilitation can be considered innovative. Implementing the combination of these training modalities has the potential to make the exercise protocol practicable and more time-efficient for $\mathrm{CAD}$ patients with $\mathrm{CAD}$. A further strength is its personalized approach. The initial power on the training device is determined based on $\mathrm{P}_{\text {peak }}$ during the ramp test; this allows an individualized control of the training intensity but could also represent a limitation of the study, as the power on the cycle ergometer does not match exactly the power of the soft robot.

\section{Ramp Test}

The data demonstrate that the CON pedaling type of interval exercise protocol is capable of producing a substantial increase in $\mathrm{VO}_{2 \text { peak }}$ in absolute and relative terms (ie, $+26 \%$ ) and $\mathrm{P}_{\text {peak }}$ (ie, $+20 \%$ ) in patients with CAD. In addition, increased values for $\mathrm{HR}_{\text {peak }}, \mathrm{Sys}_{\mathrm{BP}}$ peak , Dia $\mathrm{BP}_{\text {peak }}$, and $\mathrm{BL}_{\text {peak }}$ were found during the ramp test after the training period under the $\mathrm{CON}$ protocol. As $\mathrm{VO}_{2 \text { peak }}$ seems to reflect a continuum between health, cardiovascular disease, and death, it is important to design effective programs for exercise-induced gains of $\mathrm{VO}_{2 \text { peak }}$ [14]. The increased $\mathrm{VO}_{2 \text { peak }}$ can lead to a more active lifestyle, which can favor additional preventive benefits; this is assisted by the improved $\mathrm{P}_{\text {peak }}$, which is related to improved mobility [33].

Previous studies have shown that HIIT is an effective method for improving $\mathrm{VO}_{2 \text { peak }}$ in patients with cardiovascular diseases. A study investigated the effects of HIIT compared with continuous moderate-intensity exercise in stable patients with CAD, showing an increase of the $\mathrm{VO}_{2 \text { peak }}$ by $17.9 \%$ in the HIIT group [14]. The exercise protocol consisted of 4-minute intervals at $80 \%-90 \%$ of $\mathrm{VO}_{2 \text { peak }}$ with 3-minute active recovery periods at $50 \%-60 \%$ of $\mathrm{VO}_{2 \text { peak }}$. The increase in $\mathrm{VO}_{2 \text { peak }}$ was significantly higher in the HIIT group compared with the continuous moderate-intensity exercise group $(17.9 \%$ vs $7.9 \%)$. Similar or even better $\mathrm{VO}_{2 \text { peak }}$ improvements were shown in studies that used shorter but more intensive intervals in stable patients with CAD. A 16-week interval training, in which the intervals consisted of 2-minute work phases at $85 \%-95 \%$ of the $\mathrm{HR}$ and $\mathrm{VO}_{2}$ reserve and 2-minute rest periods at $35 \%-45 \%$ of the $\mathrm{HR}$ and $\mathrm{VO}_{2}$ reserve, led to a $15 \% \mathrm{VO}_{2 \text { peak }}$ improvement in highly functional CAD patients [34]. In addition, a 12-week interval training period, in which subjects completed ten 1 -minute phases at $89 \%$ separated by 1 -minute phases at $10 \%$ of peak power output, led to an improvement of the $\mathrm{VO}_{2 \text { peak }}$ of $20 \%$ [35]. 
The aforementioned studies underlined the importance of the training intensity to effectively increase $\mathrm{VO}_{2 \text { peak }}$. HIIT allows patients with CAD to train for longer periods of time at a higher-intensity, as it would be possible with continuous training [36]. However, protocols that use very short intervals, such as Wingate-based HIIT, may not be safe and tolerable for patients with metabolic diseases [12]. The selection of the exercise intensity, the duration of the intervals, and the use of active or passive rest have a profound influence on the acute physiological responses and exercise tolerance in patients with CAD [36]. Therefore, we decided on a protocol consisting of 1-minute work phases and 1-minute phases of passive rest; the results show that a considerable increase in $\mathrm{VO}_{2 \text { peak }}$ can be achieved with the selected training intensity and volume and their progressive increase during the 8 -week $\mathrm{CON}$ pedaling-type interval exercise protocol on the soft robot. Furthermore, the increased values for $\mathrm{HR}_{\text {peak }}$, Sys $\mathrm{BP}_{\text {peak }}$, Dia $\mathrm{BP}_{\text {peak }}$, and $\mathrm{BL}_{\text {peak }}$ during the POST ramp test show that the patient was able to exercise to a higher degree.

\section{Near-Infrared Spectroscopy}

A number of changes in $\mathrm{SmO}_{2}$ parameters during the ramp test were identified after the training period. The most noteworthy are the changes in the parameters $\Delta_{\text {deoxygenation }}$ and slope $_{\text {deoxygenation }}$, both of which have been more than doubled after training. The increased deoxygenation could indicate a better $\mathrm{O}_{2}$ extraction of the $m$. vastus lateralis during the ramp test. As the deoxygenation depends primarily on the $\mathrm{O}_{2}$ uptake of the mitochondria [37], this result could reflect the typically observed increased mitochondrial volume density within the examined muscle after the training period.

Exercise-induced changes in the skeletal muscle deoxygenation have been shown in patient populations. In postmyocardial infarction patients, it has been shown that the skeletal muscle deoxygenation was impaired [38] and that a 12-week training period led to increased deoxygenation of the $m$. vastus lateralis during the ramp test [39]. The NIRS measurement performed in addition to the determination of $\mathrm{VO}_{2 \text { peak }}$ can provide information about the peripheral adaptations in the skeletal muscle. As $\mathrm{VO}_{2 \text { peak }}$ is dependent on a central (ie, cardiac output), as well as a peripheral (ie, arteriovenous $\mathrm{O}_{2}$ difference), component, and peripheral metabolic adaptations, such as mitochondrial enzyme activity, in the skeletal muscle are critical for improving endurance performance [40], we decided to measure $\mathrm{VO}_{2 \text { peak }}$ and skeletal muscle oxygenation. Assessing skeletal muscle deoxygenation responses can be helpful to clarify peripheral impairment and its relation to reduced $\mathrm{VO}_{2 \text { peak }}$ in patients after myocardial infarction [38].

\section{Power Tests}

An increase in the average and peak power during both soft robot power tests was observed after the training period. Increasing the skeletal muscle power should be another target during cardiovascular rehabilitation because it has been shown to decline earlier and more rapidly than muscle force, and, therefore, it represents a more discriminant predictor of functional performance in older adults [41]. The observed increase can improve the ability of patients to cope with daily activities and, thus, remain active and independent. The former possibility is indicated for the CON protocol by the enhanced real power and reactive power.

\section{Protocol}

The pilot evidence from the first patients with CAD show differing adjustments in cardiovascular performance (and muscle reoxygenation) in response to the $\mathrm{ECC}$ and $\mathrm{CON}$ protocol. Specifically, we identify that $\mathrm{P}_{\text {peak }}\left(\mathrm{VO}_{2 \text { peak }}\right)$ was maintained in the patient after training with the ECC protocol, despite a moderately reduced cardiovascular performance. Hence, it is relevant to consider that the ECC patient demonstrated a better endurance training status than the $\mathrm{CON}$ patient before the training. Hence, a considerable part of improvements in the patient exercising on the $\mathrm{CON}$ protocol was related to an improvement in the cardiac function (Figure 6). In addition, it is known that at a similar mechanical power, ECC muscle work induces lower metabolic and cardiovascular responses than CON muscle work [42]. Possibly, the effects in the first 2 of our patients reflect interactions between the training state of the patients, and task-specific adaptations to the training that was matched by the mechanical output (ie, work). For the CAD patient training under the ECC protocol, the observations indicate that an increase in the endurance component, for instance, by increasing the number of work intervals, would have been beneficial to improve cardiovascular parameters.

Furthermore, we identified that peak real power was reduced with the ECC protocol and that reactive power was only improved for the right leg while both parameters were improved with the CON protocol. These observations are of interest with respect to the training status prior to entering the protocols and higher training-related increases in the average training load, and the lower metabolic stress and improved muscle reoxygenation with exhaustive exercise in the ramp test, for the ECC compared with the CON protocol. It indicates that the selected ECC exercise protocol affected the muscle strength primarily by affecting bioenergetic pathways and that this is also affected by the initial training status. For the specific ECC patient, a future closer supervision and coaching of how the task was performed with either leg would have been an option to avoid leg differences in adaptation.

Interestingly, the results show a selective improvement in the maximal oxygenation of the knee extensor muscle after recovery from the exhaustive ramp test after training under the ECC protocol; this finding can be related to the reportedly larger gains in capillary perfusion (ie, based on the capillary-to-fiber ratio) after the eccentric type of cycle endurance training [43]. It indicates that the ECC protocol may specifically enhance the rate of muscle oxygenation during recovery from exercise (reviewed in [44]).

\section{Conclusions}

To summarize, this study indicates the potential of the CON pedaling-type interval exercise protocol to increase $\mathrm{VO}_{2 \text { peak }}$, peak aerobic power output, parameters of $\mathrm{SmO}_{2}$, and anaerobic muscle power of a patient with CAD during cardiovascular rehabilitation. In addition, our first observations show that the 
ECC exercise protocol is well tolerated and maintains the peak aerobic peak aerobic power output in relation to lowered metabolic stress and improved oxygen delivery to the recruited muscle group during recovery from exhaustive exercise. The results of the ongoing study, specifically because they allow addressing the performance of each leg individually through the haptic feedback of the soft robot, may contribute to optimizing exercise protocols during cardiovascular rehabilitation.

\section{Acknowledgments}

The ongoing study is supported by a grant from the Swiss Heart Foundation.

\section{Authors' Contributions}

MF conceived the study design. CMS and DN recruited patients. KC and DL performed ramp test measurements. DPF and MVF performed NIRS measurements and drafted the manuscript. SC supervised training sessions and conducted power tests. WLP conceived and performed NIRS data processing. DPF, MVF, MF, and SR edited and revised the manuscript.

\section{Conflicts of Interest}

None declared.

\section{Multimedia Appendix 1}

Cardiorespiratory parameters pre- and posttraining for the patient, which followed the CON and ECC protocol, respectively.

[PDF File (Adobe PDF File), 253KB-Multimedia Appendix 1]

\section{Multimedia Appendix 2}

Parameters of muscle oxygen saturation $\left(\mathrm{SmO}_{2}\right)$ pre- and posttraining for the patient, which followed the CON and ECC protocol, respectively.

\section{[PDF File (Adobe PDF File), 81KB-Multimedia Appendix 2]}

\section{Multimedia Appendix 3}

Parameters of muscle performance pre- and posttraining for the patient, which followed the CON and ECC protocol, respectively.

\section{[PDF File (Adobe PDF File), 107KB-Multimedia Appendix 3]}

\section{References}

1. Townsend N, Wilson L, Bhatnagar P, Wickramasinghe K, Rayner M, Nichols M. Cardiovascular disease in Europe: epidemiological update 2016. Eur Heart J 2016 Dec 07;37(42):3232-3245. [doi: 10.1093/eurheartj/ehw334] [Medline: 27523477]

2. Federal Statistical Office. Diagnose bei Hospitalisierung. In: Statistisches Jahrbuch der Schweiz 2014. Zürich: Neue Zürcher Zeitung; 2014:338.

3. Federal Statistic Office. Sterbefälle wichtiger Todesursachen. In: Statistisches Jahrbuch der Schweiz 2014. Zürich: Neue Zürcher Zeitung; 2014:327-332.

4. Hansson G. Inflammation, atherosclerosis, and coronary artery disease. N Engl J Med 2005 Apr 21;352(16):1685-1695. [doi: 10.1056/NEJMra043430] [Medline: 15843671]

5. Herz Statistik 2016. Bottmingen, Switzerland: Swiss Heart Foundation; 2016. Zahlen und Daten über Herz-Kreislauf-Krankheiten in der Schweiz URL: https://www.swissheart.ch/fileadmin/user upload/Swissheart/Bilder Inhalt/ 5.0 Ueber uns/5.1 Aufgaben u Aktivitaeten/HerzStatistik.pdf [accessed 2018-12-17] [WebCite Cache ID 74jttfcuk]

6. Jolliffe J, Rees K, Taylor R, Thompson D, Oldridge N, Ebrahim S. Exercise-based rehabilitation for coronary heart disease. Cochrane Database Syst Rev 2001(1):CD001800. [doi: 10.1002/14651858.CD001800] [Medline: 11279730]

7. Iestra J, Kromhout D, van der Schouw YT, Grobbee D, Boshuizen H, van Staveren WA. Effect size estimates of lifestyle and dietary changes on all-cause mortality in coronary artery disease patients: a systematic review. Circulation 2005 Aug 09;112(6):924-934. [doi: 10.1161/CIRCULATIONAHA.104.503995] [Medline: 16087812]

8. Swift D, Lavie C, Johannsen N, Arena R, Earnest CP, O'Keefe JH, et al. Physical activity, cardiorespiratory fitness, and exercise training in primary and secondary coronary prevention. Circ J 2013;77(2):281-292 [FREE Full text] [Medline: 23328449]

9. Vanhees L, Geladas N, Hansen D, Kouidi E, Niebauer J, Reiner Z, et al. Importance of characteristics and modalities of physical activity and exercise in the management of cardiovascular health in individuals with cardiovascular risk factors: 
recommendations from the EACPR. Part II. Eur J Prev Cardiol 2012 Oct;19(5):1005-1033. [doi: 10.1177/1741826711430926] [Medline: 22637741]

10. Niederseer D, Niebauer J. Körperliches Training als integraler Bestandteil der Leitlinien-basierten Therapie der koronaren Herzkrankheit. Journal für Kardiologie-Austrian Journal of Cardiology 2009;16(9):327-332.

11. Piepoli MF, Hoes AW, Agewall S, Albus C, Brotons C, Catapano AL, et al. 2016 European Guidelines on cardiovascular disease prevention in clinical practice: The Sixth Joint Task Force of the European Society of Cardiology and Other Societies on Cardiovascular Disease Prevention in Clinical Practice (constituted by representatives of 10 societies and by invited experts) Developed with the special contribution of the European Association for Cardiovascular Prevention \& Rehabilitation (EACPR). Atherosclerosis 2016 Dec;252:207-274. [doi: 10.1016/j.atherosclerosis.2016.05.037] [Medline: 27664503]

12. Ribeiro P, Boidin M, Juneau M, Nigam A, Gayda M. High-intensity interval training in patients with coronary heart disease: Prescription models and perspectives. Ann Phys Rehabil Med 2017 Jan;60(1):50-57 [FREE Full text] [doi:

10.1016/j.rehab.2016.04.004] [Medline: 27346629]

13. Gibala M, Little J, Macdonald MJ, Hawley J. Physiological adaptations to low-volume, high-intensity interval training in health and disease. J Physiol 2012 Mar 01;590(5):1077-1084 [FREE Full text] [doi: 10.1113/jphysiol.2011.224725] [Medline: 22289907]

14. Rognmo Ø, Hetland E, Helgerud J, Hoff J, Slørdahl SA. High intensity aerobic interval exercise is superior to moderate intensity exercise for increasing aerobic capacity in patients with coronary artery disease. Eur J Cardiovasc Prev Rehabil 2004 Jun;11(3):216-222. [Medline: 15179103]

15. Wisløff U, Støylen A, Loennechen J, Bruvold M, Rognmo Ø, Haram PM, et al. Superior cardiovascular effect of aerobic interval training versus moderate continuous training in heart failure patients: a randomized study. Circulation 2007 Jun 19;115(24):3086-3094. [doi: 10.1161/CIRCULATIONAHA.106.675041] [Medline: 17548726]

16. Gayda M, Ribeiro P, Juneau M, Nigam A. Comparison of Different Forms of Exercise Training in Patients With Cardiac Disease: Where Does High-Intensity Interval Training Fit? Can J Cardiol 2016 Apr;32(4):485-494. [doi:

10.1016/j.cjca.2016.01.017] [Medline: 26927863]

17. Vanhees L, Fagard R, Thijs L, Staessen J, Amery A. Prognostic significance of peak exercise capacity in patients with coronary artery disease. J Am Coll Cardiol 1994 Feb;23(2):358-363 [FREE Full text] [Medline: 8294687]

18. Blair S, Barlow C, Paffenbarger JR, Gibbons L. Cardiovascular Disease and All-Cause Mortality in Men and Women. Jama 1996;276:205-210.

19. Aspenes S, Nilsen T, Skaug EA, Bertheussen GF, Ellingsen $\varnothing$, Vatten L, et al. Peak oxygen uptake and cardiovascular risk factors in 4631 healthy women and men. Med Sci Sports Exerc 2011 Aug;43(8):1465-1473. [doi: 10.1249/MSS.0b013e31820ca81c] [Medline: 21228724]

20. LaStayo P, Marcus R, Dibble L, Frajacomo F, Lindstedt S. Eccentric exercise in rehabilitation: safety, feasibility, and application. J Appl Physiol (1985) 2014 Jun 01;116(11):1426-1434 [FREE Full text] [doi: 10.1152/japplphysiol.00008.2013] [Medline: 23823152]

21. Mitchell W, Taivassalo T, Narici M, Franchi M. Eccentric Exercise and the Critically Ill Patient. Front Physiol 2017;8:120 [FREE Full text] [doi: 10.3389/fphys.2017.00120] [Medline: 28293200]

22. Katz B. The relation between force and speed in muscular contraction. J Physiol 1939 Jun 14;96(1):45-64 [FREE Full text] [Medline: 16995114]

23. Bigland-Ritchie B, Woods J. Integrated electromyogram and oxygen uptake during positive and negative work. J Physiol 1976 Sep;260(2):267-277 [FREE Full text] [Medline: 978517]

24. Franchi M, Reeves N, Narici M. Skeletal Muscle Remodeling in Response to Eccentric vs. Concentric Loading: Morphological, Molecular, and Metabolic Adaptations. Front Physiol 2017;8:447 [FREE Full text] [doi: 10.3389/fphys.2017.00447] [Medline: 28725197]

25. LaStayo P, Woolf J, Lewek M, Snyder-Mackler L, Reich T, Lindstedt S. Eccentric muscle contractions: their contribution to injury, prevention, rehabilitation, and sport. J Orthop Sports Phys Ther 2003 Oct;33(10):557-571. [doi: 10.2519/jospt.2003.33.10.557] [Medline: 14620785]

26. Lindstedt S, LaStayo P, Reich T. When active muscles lengthen: properties and consequences of eccentric contractions. News Physiol Sci 2001 Dec;16:256-261. [Medline: 11719600]

27. Hoppeler H. Moderate Load Eccentric Exercise; A Distinct Novel Training Modality. Front Physiol 2016;7:483 [FREE Full text] [doi: 10.3389/fphys.2016.00483] [Medline: 27899894]

28. Flück M, Bosshard R, Lungarella M. Cardiovascular and Muscular Consequences of Work-Matched Interval-Type of Concentric and Eccentric Pedaling Exercise on a Soft Robot. Front Physiol 2017;8:640 [FREE Full text] [doi: 10.3389/fphys.2017.00640] [Medline: 28912726]

29. ClinicalTrials.gov. 2016 Jul 16. Effect of ACE Genotype on Cardiovascular Rehabilitation (ACE-REHAB) URL: https:/ /clinicaltrials.gov/show/NCT02845063 [accessed 2018-12-19] [WebCite Cache ID 74mAFVeJQ]

30. Whipp B, Davis J, Torres F, Wasserman K. A test to determine parameters of aerobic function during exercise. J Appl Physiol Respir Environ Exerc Physiol 1981 Jan;50(1):217-221. [doi: 10.1152/jappl.1981.50.1.217] [Medline: 6782055] 
31. Fortiori Design. Introduction to Muscle Oxygen Monitoring with Moxy. Muscle Oxygen URL: https://cdn2.hubspot.net/ hub/188620/file-433442739-pdf/docs/moxy-ebook-intro-to-muscle-oxygen.pdf [accessed 2018-12-17] [WebCite Cache ID 74judgnQa]

32. Ferrari M, Muthalib M, Quaresima V. The use of near-infrared spectroscopy in understanding skeletal muscle physiology: recent developments. Philos Trans A Math Phys Eng Sci 2011 Nov 28;369(1955):4577-4590 [FREE Full text] [doi: 10.1098/rsta.2011.0230] [Medline: 22006907]

33. McPhee J, French D, Jackson D, Nazroo J, Pendleton N, Degens H. Physical activity in older age: perspectives for healthy ageing and frailty. Biogerontology 2016 Dec;17(3):567-580 [FREE Full text] [doi: 10.1007/s10522-016-9641-0] [Medline: 26936444]

34. Warburton D, McKenzie D, Haykowsky M, Taylor A, Shoemaker P, Ignaszewski AP, et al. Effectiveness of high-intensity interval training for the rehabilitation of patients with coronary artery disease. Am J Cardiol 2005 May 01;95(9):1080-1084. [doi: 10.1016/j.amjcard.2004.12.063] [Medline: 15842976]

35. Currie K, Dubberley J, McKelvie RS, MacDonald M. Low-volume, high-intensity interval training in patients with CAD. Med Sci Sports Exerc 2013 Aug;45(8):1436-1442. [doi: 10.1249/MSS.0b013e31828bbbd4] [Medline: 23470301]

36. Guiraud T, Nigam A, Gremeaux V, Meyer P, Juneau M, Bosquet L. High-intensity interval training in cardiac rehabilitation. Sports Med 2012 Jul 01;42(7):587-605. [doi: 10.2165/11631910-000000000-00000] [Medline: 22694349]

37. Muthalib M, Millet G, Quaresima V, Nosaka K. Reliability of near-infrared spectroscopy for measuring biceps brachii oxygenation during sustained and repeated isometric contractions. J Biomed Opt 2010;15(1):017008. [doi: 10.1117/1.3309746] [Medline: 20210482]

38. Takagi S, Murase N, Kime R, Niwayama M, Osada T, Katsumura T. Skeletal muscle deoxygenation abnormalities in early post-myocardial infarction. Med Sci Sports Exerc 2014 Nov;46(11):2062-2069. [doi: 10.1249/MSS.0000000000000334] [Medline: 24621961]

39. Takagi S, Murase N, Kime R, Niwayama M, Osada T, Katsumura T. Aerobic training enhances muscle deoxygenation in early post-myocardial infarction. Eur J Appl Physiol 2016 Apr;116(4):673-685 [FREE Full text] [doi: 10.1007/s00421-016-3326-x] [Medline: 26759155]

40. Bassett JD, Howley E. Limiting factors for maximum oxygen uptake and determinants of endurance performance. Med Sci Sports Exerc 2000 Jan;32(1):70-84. [Medline: 10647532]

41. Reid K, Fielding R. Skeletal muscle power: a critical determinant of physical functioning in older adults. Exerc Sport Sci Rev 2012 Jan;40(1):4-12 [FREE Full text] [doi: 10.1097/JES.0b013e31823b5f13] [Medline: 22016147]

42. Isner-Horobeti M, Dufour S, Vautravers P, Geny B, Coudeyre E, Richard R. Eccentric exercise training: modalities, applications and perspectives. Sports Med 2013 Jun;43(6):483-512. [doi: 10.1007/s40279-013-0052-y] [Medline: 23657934]

43. LaStayo P, Pierotti D, Pifer J, Hoppeler H, Lindstedt S. Eccentric ergometry: increases in locomotor muscle size and strength at low training intensities. Am J Physiol Regul Integr Comp Physiol 2000 May;278(5):R1282-R1288 [FREE Full text] [doi: 10.1152/ajpregu.2000.278.5.R1282] [Medline: 10801298]

44. Desplanches D, Amami M, Dupré-Aucouturier S, Valdivieso P, Schmutz S, Mueller M, et al. Hypoxia refines plasticity of mitochondrial respiration to repeated muscle work. Eur J Appl Physiol 2014 Feb;114(2):405-417 [FREE Full text] [doi: 10.1007/s00421-013-2783-8] [Medline: 24327174]

\author{
Abbreviations \\ BL $_{\text {peak: }}$ : peak blood lactate \\ BL: blood lactate \\ CAD: coronary artery disease \\ CON: concentric \\ CAD: coronary artery disease \\ Dia $\mathbf{B P}_{\text {peak }}$ : peak diastolic blood pressure \\ ECC: eccentric \\ HIIT: high-intensity interval training \\ $\mathbf{H R}_{\text {peak }}$ : peak heart rate \\ NIRS: near-infrared spectroscopy \\ POST: after the training period \\ $\mathbf{P}_{\text {peak }}$ : peak aerobic power output \\ PRE: before the training period \\ ROM: range of motion \\ $\mathrm{SmO}_{2}$ : muscle oxygen saturation \\ VO $_{2 \text { peak }}$ : peak oxygen uptake
}


Edited by G Eysenbach; submitted 07.05.18; peer-reviewed by A Costa e Silva; comments to author 20.09.18; revised version received 18.10.18; accepted 20.10.18; published 27.03.19

Please cite as:

Fitze DP, Franchi M, Popp WL, Ruoss S, Catuogno S, Camenisch K, Lehmann D, Schmied CM, Niederseer D, Frey WO, Flück M Concentric and Eccentric Pedaling-Type Interval Exercise on a Soft Robot for Stable Coronary Artery Disease Patients: Toward a Personalized Protocol

JMIR Res Protoc 2019;8(3):e10970

URL: https://www.researchprotocols.org/2019/3/e10970/

doi: $10.2196 / 10970$

PMID: $\underline{30916659}$

CDaniel P Fitze, Martino Franchi, Werner L Popp, Severin Ruoss, Silvio Catuogno, Karin Camenisch, Debora Lehmann, Christian M Schmied, David Niederseer, Walter O Frey, Martin Flück. Originally published in JMIR Research Protocols (http://www.researchprotocols.org), 27.03.2019. This is an open-access article distributed under the terms of the Creative Commons Attribution License (https://creativecommons.org/licenses/by/4.0/), which permits unrestricted use, distribution, and reproduction in any medium, provided the original work, first published in JMIR Research Protocols, is properly cited. The complete bibliographic information, a link to the original publication on http://www.researchprotocols.org, as well as this copyright and license information must be included. 